THE END OF CONCERN 
This page intentionally left blank 


\section{The End of Concern}

Maoist China, Activism, and Asian Studies

FABIO LANZA

DUKE UNIVERSITY PRESS

DURHAM AND LONDON 2017 
(C) 2017 Duke University Press

All rights reserved

Printed in the United States of America on acid-free paper $\infty$ Typeset in Whitman and Trade Gothic by

Graphic Composition, Inc., Bogart, Georgia

Library of Congress Cataloging-in-Publication Data

Names: Lanza, Fabio, [date] author.

Title: The end of concern : Maoist China, activism, and Asian studies / Fabio Lanza.

Description: Durham : Duke University Press, 2017. | Includes bibliographical references and index.

Identifiers: LCCN 2017019331 (print) LCCN 2017021528 (ebook)

ISBN 9780822372431 (ebook)

ISBN 9780822369325 (hardcover : alk. paper)

ISBN 9780822369479 (pbk. : alk. paper)

Subjects: LCSH: Committee of Concerned Asian Scholars.

| China_-Study and teaching (Higher) - United States -

History-2oth century. | China-Relations-United States-

History-2oth century. | United States-Relations_ChinaHistory-2oth century.

Classification: LCC DS734.97.U6 (ebook) | LCC DS734.97.U6 L35 2017 (print) | DDC 951.05071/173-dc23

LC record available at https://lccn.loc.gov/2017019331

Cover art: Design and illustration by Matthew Tauch. 
TO SANDY, IN MEMORIAM 
This page intentionally left blank 